\title{
Relationship between exhaled air temperature and exhaled nitric oxide in childhood asthma
}

\author{
G.L. Piacentini*, A. Bodini*, L. Zerman*, S. Costella*, L. Zanolla*, D.G. Peroni*, A.L. Boner*
}

Relationship between exhaled air temperature and exhaled nitric oxide in childhood asthma. G. L. Piacentini, A. Bodini, L. Zerman, S. Costella, L. Zanolla, D. G. Peroni, A.L. Boner. (C) ERS Journals Ltd 2002.

ABSTRACT: Airway inflammation is a characteristic of asthma. Exhaled nitric oxide (eNO) has been demonstrated to be related to actual levels of airway inflammation in asthmatic patients. The purpose of this study was to investigate whether the temperature of exhaled air is related to eNO levels.

Temperature of exhaled air and eNO were measured in 52 asthmatic children with a cross-sectional design.

A significant relationship was demonstrated between eNO and temperature of peak and plateau exhaled air temperature. The relationship between both the peak and the plateau values and eNO was more evident when it was corrected for environmental temperature.

These results suggest a relationship between exhaled nitric oxide and the temperature of exhaled air in asthmatic patients not treated with systemic steroids. Eur Respir J 2002; 20: 108-111.
*Dept of Pediatrics, University of Verona and "Dept of Cardiology, Istituto Pio XII, Misurina, Italy.

Correspondence: A.L. Boner, Dipartimento di Pediatria, Policlinico G.B. Rossi, 37134 Verona, Italy. Fax: 39458200993 E-mail: boner@borgoroma.univr.it

Keywords: Airway inflammation asthma in childhood exhaled air temperature exhaled nitric oxide

Received: April 202001 Accepted after revision: February 4 2002
Asthma is an inflammatory disease of the airways characterised by cellular infiltration and oedema of the mucosa, epithelial damage, mucus production and plasma exudation [1-3].

Bronchoscopy with biopsies is regarded as the most reliable method of evaluating the level of airway inflammation in asthmatic patients [4], but it is hardly applicable as a routine test, particularly in children. Therefore, a variety of noninvasive markers have been proposed [5]. Exhaled nitric oxide (eNO) has been demonstrated to be related to the actual level of airway inflammation [6, 7] and to reflect the effect of treatment with anti-inflammatory agents [8,9].

By directly viewing the airway of an asthmatic patient through a bronchoscope, at least two of the characteristics of inflammation stated by Celsus ( 30 b.c. -38 a.c.), i.e. rubor and (oedema of the mucosa) tumor, can be observed. On this basis, and due to the current knowledge of asthma pathology, it was hypothesised that the third of Celsus' cardinal signs of inflammation, i.e. calor, could be a reflection of the actual degree of airway inflammation in asthmatic patients.

To test this hypothesis, the relationship of the temperature of the exhaled air and eNO in asthmatic children was investigated.

\section{Material and methods}

\section{Patients}

Fifty-two allergic asthmatic children (age 6-15 yrs) were evaluated at the Istituto Pio XII (Misurina, Italian Dolomites) with a cross-sectional study design.
None of the children had infectious diseases in the 4 weeks before the study day and none of them had received oral steroids for $\geqslant 2$ months previously. Thirty-five of the patients were treated with $\beta_{2}$-agonists alone, as required, and they had not been receiving any regular treatment with inhaled steroids for 2 months before the study. Seventeen of the patients were receiving regular treatment with inhaled steroids, either fluticasone $200 \mu \mathrm{g} \cdot \mathrm{day}^{-1}$ or beclomethasone $400 \mu \mathrm{g} \cdot \mathrm{day}^{-1}$.

The study was approved by the ethical committee of the Istituto Pio XII. The patients and their parents were informed about the purposes and methods of the study and they gave their consent before the enrolment.

\section{Nitric oxide measurement}

eNO was measured by chemiluminescence analyser (Logan LR 2149; Logan, Rochester, Kent, UK) before spirometry was performed $[10,11]$.

Briefly, the subjects were asked to perform a single slow exhalation starting from total lung capacity through a mouthpiece, against a resistance (mouth pressure $>5 \mathrm{cmH}_{2} \mathrm{O}$ ), and with a biofeedback used to maintain a $5-6 \mathrm{~L} \cdot \mathrm{min}^{-1}$ steady flow. This method allowed for the separation of the nasopharynx from the oropharynx by the soft palate, hence preventing the contamination of eNO with nasal NO. This method has been applied successfully both in adults and children. NO values were measured at the plateau of the end-exhaled reading and expressed in parts per billion [12-14]. 


\section{Exhaled air temperature evaluation}

The temperature of the exhaled air was evaluated by a high performance temperature indicator (DP41-TC; Omega Engineering Ltd, CA, US) connected to a thermocouple (COCO-0.001, Omega Engineering Ltd; response time in still air $0.05 \mathrm{~s}$ ) during a slow expiratory act. The thermocouple was fitted in a $\mathrm{T}$ plastic tube with replaceable mouthpieces in order to keep the distance from the mouth of the patients constant. The maximum reading value, defined as peak expiratory temperature (PET) and the plateau value at the end of the expiration (PLET) were recorded.

The patient was asked to perform a slow expiratory manoeuvre, similar to the manoeuvre the patients were used to performing when assessing vital capacity by spirometry. Three evaluations with samples taken at 5-min intervals were performed and the mean of the two closest values was used for analysis. All the measurements were performed early in the morning, between 07:30-09:00 h, before the children had drunk anything or performed exercise, in order to minimise the possible effects of extraneous factors. Body temperature was measured at the ear by an instant thermometer (ThermoScan pro LT, Type 6007, professional model; Braun, ThermoScan Inc., San Diego, CA, USA).

Environmental temperature and humidity were controlled throughout the study period.

\section{Statistical analysis}

The repeatability of the temperature measurement was evaluated by calculating intra-individual coefficient of variation.

Since the analysis of frequency distribution for PET and PLET failed to show a normal distribution, all the analyses were performed by nonparametric tests.

Relationships between eNO values and PET or PLET were performed using the Spearman Rank correlation coefficient. The correlations between eNO and PET or PLET used both raw data and normalised data, which were obtained by subtracting the environmental temperature from the actual PET or PLET value. The normalised values are expressed as nPET and nPLET.

Comparison between steroid-treated and steroiduntreated patients was performed by Mann-Whitney
U-test. The level of probability was considered significant if $\mathrm{p}<0.05$.

\section{Results}

Environment temperature ranged between 22 and $23^{\circ} \mathrm{C}$ and relative humidity was between 60 and $65 \%$ throughout the study period. Body temperature ranged between 36.5 and $37.3^{\circ} \mathrm{C}$, which is considered normal for the method of measurement. No correlation was observed between either PET or PLET and the body temperature of the children. The coefficient of variation within subjects for PET was $2.8 \%( \pm 0.25)$ and for PLET $2.23 \%( \pm 0.23)$.

The mean values for eNO and temperature in the study group are reported in table 1 . No significant difference was observed for eNO and exhaled air temperature between either steroid-treated and steroiduntreated children.

Considering the whole group of 52 patients, there was a significant relationship between PLET and eNO $(\mathrm{r}=0.46, \mathrm{p}=0.012)$, and PET was moderately but still significantly related to eNO $(r=0.27, p=0.039)$. In the steroid-untreated children $(n=35)$ the relationship between PLET and eNO still showed a moderately significant correlation $(\mathrm{r}=0.43, \mathrm{p}=0.126)$, whereas PET versus eNO was not significant $(\mathrm{r}=0.23$, NS), probably due to the reduction in the number of cases. In the group of children treated with inhaled steroids $(n=17)$, PET versus eNO showed $\mathrm{r}=0.37$ (Ns) and $\mathrm{PLET}$ versus NO showed $r=0.45$ (ns). Since, in the last group, the r-values are still comparable to those observed in the larger group, it is not possible to exclude the fact that he lack in significance could be due to the reduction in the number of cases.

When considering the values corrected for environmental temperature, the relationships with eNO were more evident. In the whole group, nPET versus $\mathrm{eNO}$ was $\mathrm{r}=0.42(\mathrm{p}=0.0027)$ and $\mathrm{nPLET}$ versus eNO was $\mathrm{r}=0.54$ ( $\mathrm{p}=0.0001)$ (fig. 1). In the steroid-untreated group nPET versus eNO was $\mathrm{r}=0.337(\mathrm{p}=0.0503)$ and nPLET versus eNO was $\mathrm{r}=0.513(\mathrm{p}=0.028)$. Similarly in the steroid-treated group nPET versus eNO was $\mathrm{r}=0.547(\mathrm{p}=0.294)$ and nPLET versus $\mathrm{eNO}$ was $\mathrm{r}=0.552$ $(\mathrm{p}=0.276)$.

Table 1. - Descriptive values for exhaled nitric oxide (eNO) and exhaled air temperature in the study group

\begin{tabular}{|c|c|c|c|c|c|c|}
\hline & Subjects $\mathrm{n}$ & eNO & PET & PLET & nPET & nPLET \\
\hline $\begin{array}{l}\text { Whole group } \\
\text { mean } \pm \text { SEM } \\
\text { median }(\mathrm{Q} 1 ; \mathrm{Q} 3)\end{array}$ & 52 & $\begin{array}{c}15.0 \pm 1.3 \\
13.2(9.9 ; 8.9)\end{array}$ & $\begin{array}{c}32.4 \pm 0.2 \\
32.5(29.5 ; 33.4)\end{array}$ & $\begin{array}{c}31.1 \pm 0.3 \\
29.9(28.4 ; 32.3)\end{array}$ & $\begin{array}{c}10.1 \pm 0.3 \\
10.0(9.2 ; 11.2)\end{array}$ & $\begin{array}{c}8.8 \pm 0.3 \\
9.2(7.5 ; 9.9)\end{array}$ \\
\hline $\begin{array}{l}\text { Steroid-untreated } \\
\text { mean } \pm \text { SEM } \\
\text { median }(\mathrm{Q} 1 ; \mathrm{Q} 3)\end{array}$ & 35 & $\begin{array}{c}16.1 \pm 1.6 \\
13.2(10.1 ; 19.7)\end{array}$ & $\begin{array}{c}32.6 \pm 0.3 \\
32.6(29.2 ; 33.8)\end{array}$ & $\begin{array}{c}31.3 \pm 0.3 \\
31.4(29.8 ; 32.4)\end{array}$ & $\begin{array}{c}10.3 \pm 0.3 \\
10.1(9.6 ; 11.3)\end{array}$ & $9.3(7.7 ; 10.1)$ \\
\hline $\begin{array}{l}\text { Steroid-treated } \\
\text { mean } \pm \text { SEM } \\
\text { median }(\mathrm{Q} 1 ; \mathrm{Q} 3)\end{array}$ & 17 & $\begin{array}{c}12.7 \pm 2.0 \\
10.6(5.7 ; 15.4)\end{array}$ & $\begin{array}{c}32.1 \pm 0.3 \\
32.5(31.1 ; 33.1)\end{array}$ & $\begin{array}{c}30.8 \pm 0.4 \\
31.2(29.8 ; 32.3)\end{array}$ & $\begin{array}{c}9.6 \pm 0.4 \\
9.5(8.8 ; 10.8)\end{array}$ & $\begin{array}{c}8.4 \pm 0.4 \\
9.2(6.8 ; 9.8)\end{array}$ \\
\hline
\end{tabular}

PET: peak expiratory temperature; PLET: plateau value at the end of expiratory; nPET: normalised PET; nPLET: normalised PLET; Q1: upper quartile; Q3: lower quartile. 


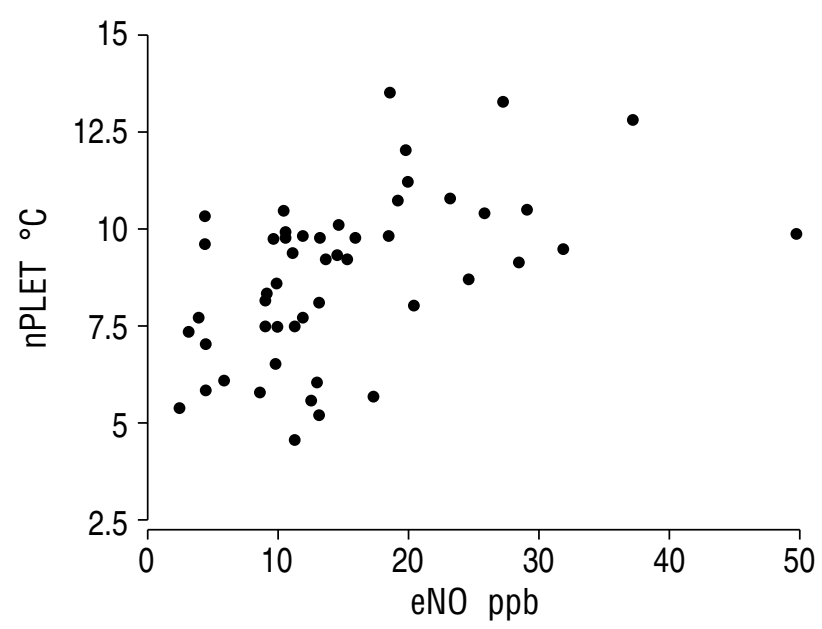

Fig. 1.- Relationship between normalised plateau value at the end of the expiration temperature (nPLET) and exhaled nitric oxide (eNO) in the whole study group.

\section{Discussion}

In this study, significant positive correlations were found between the temperature of exhaled air and eNO in allergic asthmatic children. This was a preliminary study aimed at exploring the hypothesis that airway inflammation could be accompanied by an increase in temperature of exhaled air from asthmatic patients. The rationale of this hypothesis can be found both in increased vascularity and cell metabolism, which typically occurs in the inflamed airway wall in asthmatic subjects [1-3]. A possible relationship between the temperature of exhaled air and airway inflammation has recently been suggested by other groups $[15,16]$.

eNO was elected as a surrogate marker of airway inflammation. Other more invasive assessments of airway inflammation might not be approved by the ethics committee, in the absence of any preliminary indicative results. However, since the relationship between eNO and airway inflammation is still under study and somewhat tenuous [8, 17], further studies against "gold standards", such as biopsies or sputum eosinophilia [18], need to be performed to validate the hypothesis that exaled air temperature can represent a marker of airway inflammation.

The present data suggest a better concordance between eNO levels and the end-expiratory air temperature. It is tempting to speculate that this could be based on the fact that the eNO values were measured at the end of the expiratory manoeuvre, which is representative of NO sampling in the most distal airways [13].

The children performed the manoeuvres for exhaled air temperature measurements easily and a very low coefficient of variability was found in the same subject. With this experimental design it was not possible to evaluate the relationship between airflow and exhaled air temperature, which will need to be addressed in further studies. The control of exhalation flow should further reduce the variability of the measurements.

Further studies are also required in order to evaluate whether the level of concordance between the investigated parameters could be increased by controlling environmental temperature, exhaled air flow and pressure.

In conclusion, the results of this preliminary study show that exhaled air temperature is related to exhaled nitric oxide levels in asthmatic children. These results, therefore, suggest that the level of exhaled air temperature could represent a potential method for the assessment of airway inflammation in asthmatic patients and encourage a new field of investigation in asthma research to be opened.

\section{References}

1. Kay AB. Asthma and inflammation. J Allergy Clin Immunol 1991; 87: 893-899.

2. Djukanovic R, Roche WR, Wilson JW, Baesley CR, Twentyman OP, Holgate ST. Mucosal inflammation in asthma. Am Rev Respir Dis 1990; 142: 434- 457.

3. Busse WW. Inflammation and asthma: the cornerstone of the disease and target of therapy. J Allergy Clin Immunol 1998; 102: S17-S22.

4. Bousquet J, Jeffery PK, Busse WW, Johnson M, Vignola AM. Asthma from bronchoconstriction to airway inflammation and remodelling. Am J Respir Crit Care Med 2000; 161: 1720-1745.

5. Holgate ST. Biomarkers of asthma. Lancet 1998; 351: $1300-1301$.

6. Kharitonov SA, Yates DH, Robbins RA, LoganSinclair R, Shinebourne EA, Barnes PJ. Increased nitric oxide in exhaled air of asthmatic patients. Lancet 1994; 343: 133-135.

7. Jatakanon A, Lim S, Kharitonov S, Chung K, Barnes PJ. Correlation between exhaled nitric oxide, sputum eosinophils and methacholine responsiveness in patients with mild asthma. Thorax 1998; 53: 9195.

8. Mattes J, van's Gravesande S, Reining U, et al. NO in exhaled air is correlated with markers of eosinophilic airway inflammation in corticosteroid-dependent childhood asthma. Eur Respir J 1999; 13: 1391-1395.

9. Jatakanon A, Kharitonov SA, Lim S, Barnes PJ. Effect of differing doses of inhaled budesonide on markers of airway inflammation in patients with mild asthma. Thorax 1994; 54: 108-114.

10. Kharitonov SA, Yates DH, Chung KF, Barnes PJ. Changes in the dose of inhaled steroid affect exhaled nitric oxide levels in asthmatic patients. Eur Respir $J$ 1996; 9: 196-201.

11. Kharitonov SA, Yates DH, Barnes PJ. Inhaled glucocorticoids decrease nitric oxide in exhaled air of asthmatic patients. Am J Respir Crit Care Med 1996; 153: 454 457.

12. Lundberg JON, Weitzberg E, Lundberg JM, Alving K. Nitric oxide in exhaled air. Eur Respir J 1996; 9: 2671-2680.

13. Kharitonov SA, Barnes PJ. Exhaled nitric oxide: a marker of airway inflammation?. Curr Opin Anesthesiol 1996; 9: 542-548.

14. Kharitonov SA, Fan Chung K, Evans D, O'Connor $\mathrm{BJ}$, Barnes PJ. Increased exhaled nitric oxide in asthma is mainly derived from the lower respiratory tract. Am J Respir Crit Care Med 1996; 153: 17731780. 
15. Paredi P, Word S, Craner D, Barnes PJ, Kharitonov SA. Faster rise in exhaled breath temperature gradients in asthma. Am J Respir Crit Care Med 2001; 163: A47.

16. Paredi $\mathrm{P}$, Kharitonov SA, Willson K, Barnes PJ. Measurement of exhaled breath temperature gradients. Am J Respir Crit Care Med 2001; 163: A420.

17. Piacentini GL, Bodini A, Costella S, et al. Exhaled nitric oxide and sputum eosinophil markers of inflammation in asthmatic children. Eur Respir $J$ 1999; 13: 1386-1390.

18. Haczku A, Takeda K, Hamelmann E, et al. CD23 exhibits negative regulatory effects on allergic sensitization and airway hyperresponsivness. Am J Respir Crit Care Med 2000; 161: 952-960. 